\title{
Prestação de Portugal nos Jogos Olímpicos de Pequim 2008
}

\author{
Alfredo J. Silva
}

\section{RESUMO}

Introdução: O valor desporto de rendimento de cada nação é aferido, entre outros acontecimentos, no maior evento desportivo, os Jogos Olímpicos.

O objectivo do artigo é avaliar a prestação de Portugal nos Jogos Olímpicos de Pequim 2008 no plano desportivo e financeiro e comparar com a prestação obtida nos Jogos Olímpicos de Atenas 2004.

Metodologia: A metodologia adoptada no estudo consiste na recolha de informação de várias fontes documentais.

Resultados: Os três objectivos desportivos fixados para

Portugal nos Jogos Olímpico de Pequim 2008, não foram atingidos.

O desempenho desportivo de Portugal traduzido no número de medalhas e de diplomas teve um nível inferior em Pequim 2008 do que em Atenas 2004.

Para a execução do Projecto Pequim 2008 foi concedido ao Comité Olímpico de Portugal uma verba 12.142.876€, mas o montante afectado às federações desportivas destinado à preparação dos praticantes desportivos e às bolsas, foi inferior em 154.241€, ao correspondente no Projecto Atenas 2004.

No período de 12 anos (Atlanta 1996 - Pequim 2008) os meios financeiros aplicados na preparação olímpica aumentaram em $100 \%$, não tendo os resultados desportivos acompanhado com qualquer crescimento.

Palavras-chave: jogos olímpicos, Pequim 2008, comité olímpico de Portugal, resultados olímpicos de Portugal
Escola Superior de Desporto de Rio Maior

Portugal

\begin{abstract}
Performance of Portugal in the Beijing 2008 Olympic Games

Introduction: The value at the top level sport of each nation is checked, among other events, in the largest sport event, the Olympic Games. The propose of the study is to evaluate the performance of Portugal in the Olympic Games Beijing 2008 in the sport and financial level and to compare with the performance obtained in the Olympic Games of Athena 2004.

Methodology: The methodology use in the study consists in the it collects of information of several documental sources.

Results: The three sport goals fastened for Portugal in the Beijing 2008 Olympic Games, they were not reached.

The sport performance of Portugal translated in the number of medals and of graduate classifications he had an inferior level in Beijing 2008 than in Athena 2004.

For the execution of Project Beijing 2008 was granted to Olympic Committee of Portugal a budget 12.142.876 €, but the amount affected to the sport federations destined to the sport preparation and the bags, it was inferior in $154.241 €$, to the correspondent in Project Athena 2004.

In the period of 12 years (Atlanta 1996 - Beijing 2008) the applied financial means in the olympic preparation increased in 100\%, doesn't tend the sport results accompanied with any growth.
\end{abstract}

Key-words: Beijing 2008, olympic games, Portugal olympic committee, olympic results of Portugal 


\section{INTRODUÇÃO}

O valor desporto de rendimento de cada nação é aferido, entre outros acontecimentos, no maior evento desportivo do mundo, os Jogos Olímpicos.

Os Jogos Olímpicos são quadrienalmente um assunto dimensionado à escala mundial e objecto de avaliação pelos mais diferentes intervenientes e pelas mais distintas perspectivas.

Pela razão dos tempos que vivemos é um assunto de natureza prioritária em vários planos, onde a comunicação social assume o seu papel, mediante análises e comentários, nem sempre com a profundidade desejável, induz muitas vezes a reacções intempestivas por parte, quer dos organismos desportivos, quer dos governos.

O número de medalhas que os países obtêm, há-de sempre manifestar o valor do desporto de rendimento desses países e posiciona-os na globalizada escala da competitividade do desporto mundial.

$\mathrm{O}$ artigo tem por objectivo avaliar a prestação de Portugal nos Jogos Olímpicos de Pequim 2008 e comparar com a prestação obtida nos Jogos Olímpicos de Atenas 2004. A avaliação dos resultados obtidos e dos objectivos fixados, abrangerá o plano desportivo e financeiro e incluirá a comparação dos 27 países da União Europeia.

A preocupação principal consiste em avaliar o desempenho dos praticantes desportivos e das federações desportivas nos Jogos Olímpicos de Pequim 2008, confrontando os resultados alcançados com os objectivos que se encontravam estabelecidos e com os financiamentos que foram concedidos.

\section{METODOLOGIA}

A metodologia adoptada no estudo consistiu na recolha e registo de informação de várias fontes documentais: do relatório dos Jogos Olímpicos de Atenas 2004 elaborado pelo Instituto do Desporto de Portugal em 2004, dos elementos fornecidos pelo Instituto do Desporto de Portugal, relativamente aos financiamentos concedidos para os Jogos Olímpicos de Pequim 2008, no período de 2005 a 2008, dos relatórios dos anos de 2005, 2006 e 2007 do programa de preparação olímpica do Comité Olímpico de Portugal e dos resultados desportivos obtidos por Portugal nos Jogos Olímpicos de Pequim 2008, que decorreram de 8 a 24 de Agosto de 2008 em Pequim.

\section{RESULTADOS}

Praticantes desportivos e federações desportivas que participaram nos Jogos Olímpicos Pequim 2008

Das 29 federações desportivas que integram disciplinas incluídas no programa oficial dos Jogos Olímpicos de Verão 2008, 17 estiveram representadas nos Jogos Olímpicos de Pequim 2008, o que corresponde a $58 \%$ das federações desportivas. Doze federações desportivas (42\%) não estiveram representadas nos Jogos Olímpicos.

Os praticantes desportivos que integraram a missão de Portugal aos Jogos Olímpicos foram em número de 77. A federação desportiva que maior número de praticantes desportivos levou aos Jogos Olímpicos foi a de Atletismo com 27 praticantes, que corresponde a mais de $1 / 3$ dos praticantes na missão (35\%).

Relativamente ao género, 51 dos 77 praticantes desportivos eram do sexo masculino, valor que corresponde a $66 \%$.

As 17 modalidades participantes eram todas de desportos individuais. Não houve participação de modalidades de desportos colectivos.

O nível desportivo dos praticantes desportivos que participaram nos Jogos Olímpicos de Pequim 2008 era bastante diversificado. Dos 77 praticantes que participaram nos Jogos Olímpicos de Pequim 2008, $56(73 \%)$ estavam integrados no Projecto Pequim $2008^{(4)}$, beneficiaram de especiais apoios e foram sujeitos ao programa de preparação desportiva Pequim 2008, com vista a assegurar a obtenção de resultados relevantes.

Nove praticantes integravam o nível I de desempenho, que corresponde à categoria de medalhado em Jogos Olímpicos. 15 praticantes estavam integrados no nível II, correspondente à categoria de finalista ou diploma ( $4 .^{\circ}$ a $8 .^{\circ}$ lugar) em Jogos Olímpicos. Um grupo mais extenso de 21 praticantes pertencia ao nível III que corresponde à categoria de semi-finalista $\left(9 .^{\circ}\right.$ a $16 .^{\circ}$ lugar) em Jogos Olímpicos. E ainda os níveis de desempenho IV e Qualificado (Q) com 32 praticantes desportivos (41\%), que correspondem às categorias inferiores de desempenho desportivo.

Resultados obtidos pelos praticantes desportivos, federações desportivas e mérito das classificações Em termos de resultados obtidos pelos praticantes 
Quadro 1. Praticantes desportivos, federações desportivas e participação nos Jogos Olímpicos

\begin{tabular}{|c|c|c|c|c|c|c|}
\hline \multicolumn{7}{|c|}{ Praticantes desportivos e federações desportivas e participação nos Jogos Olímpicos } \\
\hline & \multirow[b]{2}{*}{$\begin{array}{l}\text { Federações que } \\
\text { participaram nos Jogos } \\
\text { Olímpicos }\end{array}$} & \multicolumn{3}{|c|}{ Praticantes desportivos } & & \multirow[b]{2}{*}{$\begin{array}{l}\text { Federações que não participaram nos } \\
\text { Jogos Olímpicos }\end{array}$} \\
\hline & & Masc. & Fem. & Total & & \\
\hline 1 & Atletismo & 13 & 14 & 27 & 1 & Andebol \\
\hline 2 & Natação & $?$ & 3 & 10 & 2 & Basebol \\
\hline 3 & Vela & 8 & & 8 & 3 & Basquetebol \\
\hline 4 & Judo & 3 & 2 & 5 & 4 & Boxe \\
\hline 5 & Canoagem & 1 & 3 & 4 & 5 & Halterofilismo \\
\hline 6 & Triatlo & 2 & 1 & 3 & 6 & Hóquei \\
\hline$?$ & Equestre & 3 & & 3 & $?$ & Pentatlo Moderno \\
\hline 8 & Ténis de Mesa & 3 & & 3 & 8 & Futebol \\
\hline 9 & Remo & 2 & & 2 & 9 & Ginástica \\
\hline 10 & Trampolins & 1 & 1 & 2 & 10 & Lutas Amadoras \\
\hline 11 & Badmington & 1 & 1 & 2 & 11 & Voleibol \\
\hline 12 & Ciclismo & 2 & & 2 & 12 & Ténis \\
\hline 13 & Esgrima & 1 & 1 & 2 & & $42 \%$ das federações \\
\hline 14 & Taekwondo & 1 & & 1 & & \\
\hline 15 & Tiro & 1 & & 1 & & \\
\hline 16 & Tiro com Arco & 1 & & 1 & & \\
\hline \multirow[t]{3}{*}{17} & Tiro com Armas de Caça & 1 & & 1 & & \\
\hline & $58 \%$ das federações & & & & & \\
\hline & Total & 51 & 26 & 77 & & \\
\hline
\end{tabular}

desportivos verificamos que o desempenho de Portugal em Pequim 2008 ao nível das classificações dos 3 lugares de pódio foi de 2 medalhas o que corresponde a $2,5 \%$, das 79 classificações teoricamente possíveis de obter. Dos 9 praticantes desportivos que integravam o nível I, 2 (22\%) concretizaram o objectivo ao terem conquistado classificações correspondentes ao seu nível.

$\mathrm{Na}$ categoria dos diplomas (do $4 .^{\circ}$ ao $8 .^{\circ}$ lugar) foram obtidos 7 lugares que correspondem a $8,8 \%$ dos resultados. Dos 15 praticantes desportivos que integravam o nível II, 6 praticantes $(40 \%)$ atingiram o objectivo. Ou seja, verificamos que $60 \%$ dos praticantes do nível II não obteve classificações correspondentes ao seu nível.

$\mathrm{Na}$ categoria do $9 .^{\circ}$ ao $16 .^{\circ}$ lugar foram obtidas 15 classificações que correspondem a $19 \%$ dos resulta- dos. Dos 21 praticantes desportivos que integravam o nível III de desempenho, 4 (19\%) conseguiram esse objectivo e conquistaram classificações correspondentes ao seu nível, enquanto $81 \%$ não conseguiram esse objectivo.

As 55 classificações acima do $16 .^{\circ}$ lugar ou desistências correspondem a $70 \%$ dos resultados.

Verificamos que 23 praticantes dos níveis desportivos superiores - I, II e III - obtiveram classificações neste segmento não correspondendo a um desempenho compatível com o seu desportivo.

Dos 24 praticantes que integraram os níveis I e II, apenas 9 (38\%) conseguiram obter classificações até ao $8 .^{\circ}$ lugar. Neste 2 níveis, $62 \%$ dos praticantes desportivos não conseguiu concretizar o seu objectivo, mediante a obtenção de uma classificação correspondente ao seu nível desportivo. 
Quadro 2. Classificações dos praticantes desportivos por nível desportivo

\begin{tabular}{|c|c|c|c|c|c|c|}
\hline & \multicolumn{5}{|c|}{ Nível desportivo } & \multirow{2}{*}{ Total } \\
\hline & 1 & 11 & III & IV & 0 & \\
\hline N. ${ }^{\circ}$ de praticantes & 9 & 15 & 21 & 11 & 21 & $7 ?(100 \%)$ \\
\hline N. ${ }^{\circ}$ e de medalhas & $2(25 \%)$ & 0 & 0 & 0 & 0 & $2(2,5 \%)$ \\
\hline N. ${ }^{\circ}$ \% de diplomas & 1 & $3[21 \%]$ & 2 & 1 & 0 & $7(8,8 \%)$ \\
\hline N. ${ }^{\circ}$ class. de $9 .{ }^{\circ}$ a $16 .^{\circ}$ & 3 & 8 & $4(17 \%)$ & 0 & 0 & $15[19 \%]$ \\
\hline N. ${ }^{\circ}$ class. acima de $16 .{ }^{\circ}$ e desistências & 2 & 3 & 18 & 10 & 22 & $55[70 \%]$ \\
\hline Total de class. possíveis & 8 & 14 & 24 & 11 & 22 & $79(100 \%)$ \\
\hline
\end{tabular}

Quadro 3. Mérito desportivo e clas sificações obtidas nos Jogos Olímpicos Pequim 2008

\begin{tabular}{|c|c|c|c|}
\hline \multicolumn{4}{|c|}{ Mérito desportivo e classificações obtidas nos Jogos Olímpicos Pequim 2008} \\
\hline Classificação & $\begin{array}{l}\text { N. }{ }^{0} \text { de classificações } \\
\text { obtidas }\end{array}$ & $\begin{array}{l}\text { Pontos a atribuir } \\
\text { por classificação }\end{array}$ & Pontuação obtida \\
\hline Ouro & 1 & 8 & 8 \\
\hline Prata & 1 & $?$ & $?$ \\
\hline Bronze & & 6 & \\
\hline sub-total & 2 & & 15 \\
\hline 4. ${ }^{\circ}$ lugar & 1 & 5 & 5 \\
\hline $5 .{ }^{\circ}$ lugar & & 4 & \\
\hline 6. ${ }^{\circ}$ lugar & & 3 & \\
\hline 7. ${ }^{\circ}$ lugar & 2 & 2 & 4 \\
\hline 8. ${ }^{\circ}$ lugar & 4 & 1 & 4 \\
\hline sub-total & 7 & & 13 \\
\hline Total & 9 & & 28 \\
\hline
\end{tabular}

Nos níveis I, II e III, verificou-se uma situação ainda mais desfavorável, na qual $80 \%$ dos praticantes desportivos não teve uma prestação desportiva compatível com o seu nível desportivo.

Para apreciação do mérito desportivo das classificações obtidas foi adoptado o quadro de pontuação, que vem sendo utilizado desde os Jogos de Atlanta 1996, que permite avaliar, quer a prestação de Portugal e dos países, quer das várias federações desportivas participantes, em função das classificações obtidas pelos praticantes desportivos nas respectivas competições.

A pontuação de mérito desportivo obtida por Portugal foi de 28 pontos, resultante de 2 medalhas e de 7 diplomas. Saliente-se que na categoria do 9. ao $16 .^{\circ}$ lugar foram obtidas 15 classificações. As federações desportivas que obtiveram melhores resultados de mérito desportivo foram a de Atletismo, a de Vela e a de Triatlo. Um segundo grupo de federações integra a de Judo e a de Taekwondo, ao qual sucede a federação de Remo. Das 17 federações desportivas presentes nos Jogos Olímpicos de Pequim 2008, 6 (35\%) conseguiram obter classificações até ao $8 .^{\circ}$ lugar. Pelo contrário 11 federações desportivas (65\%) não obtiveram qualquer classificação até ao $8 .^{\circ}$ lugar. Mais de metade (53\%) das federações desportivas presentes ${ }^{(6)}$ não conseguiu obter qualquer classificação até ao $16 .^{\circ}$ lugar. 


\begin{tabular}{|c|c|c|c|}
\hline \multicolumn{4}{|c|}{ Quadro do mérito desportivo por federação desportiva } \\
\hline & Federação & $\begin{array}{l}\text { N. }{ }^{\circ} \text { de class. até ao } 8 .^{\circ} \\
\text { lugar }\end{array}$ & N. ${ }^{\circ}$ pontos obtidos \\
\hline 1 & Atletismo & 2 & $9(32 \%)$ \\
\hline 2 & Vela & 3 & $?(25 \%)$ \\
\hline 3 & Triatlo & 1 & $?(25 \%)$ \\
\hline 4 & Judo & 1 & $2(7 \%)$ \\
\hline 5 & Taekwondo & 1 & $2(7 \%)$ \\
\hline 6 & Remo & 1 & $1(3,6)$ \\
\hline$?$ & Canoagem & & \\
\hline 8 & Natação & & \\
\hline 9 & Tiro com Armas Caça & & \\
\hline 10 & Trampolins & & \\
\hline 11 & Ciclismo & & \\
\hline 12 & Equestre & & \\
\hline 13 & Esgrima & & \\
\hline 14 & Tiro & & \\
\hline 15 & Badminton & & \\
\hline 16 & Ténis Mesa & & \\
\hline \multirow[t]{2}{*}{17} & Tiro Arco & & \\
\hline & Total & 9 & $28(100 \%)$ \\
\hline
\end{tabular}

\section{Objectivos de Portugal para os \\ Jogos Olímpicos de Pequim 2008}

Os objectivos desportivos de Portugal para os Jogos

Olímpicos de Pequim 2008, foram fixados no contratoprograma de desenvolvimento desportivo n. ${ }^{\circ}$

48/2005(2), celebrado em 27 de Janeiro de 2005, entre o Comité Olímpico de Portugal e o Estado Português, através do Instituto do Desporto de Portugal. Esse contrato foi publicado no Diário da República N. ${ }^{\circ} 70$, de 11 de Abril de 2005, 2. ${ }^{\text {a }}$ série, e era seu objecto a execução do Programa de Preparação Olímpica para os Jogos Olímpicos de Pequim 2008. A execução desse programa de actividades tinha os seguintes objectivos desportivos: 1) Obter cinco classificações de pódio (medalhas);

2) Obter doze classificações correspondentes a diplomas (do 4. ${ }^{\circ}$ ao 8..$^{\circ}$ lugar); e

3) Estar representado com dezoito modalidades desportivas.
As metas dos objectivos formulados, considerando o anterior desempenho de Portugal nos Jogos Olímpicos de Atenas 2004 manifestam incrementos na ordem de 2 medalhas, (67\%), 2 diplomas (20\%) e uma modalidade desportiva presente (6\%). Terminados os Jogos Olímpicos e antes de apreciar o grau de cumprimento dos objectivos desportivos, interessa referir que o Estado Português, através do Instituto do Desporto de Portugal cumpriu as suas obrigações no âmbito do contrato. Ou seja, transferiu para o Comité Olímpico de Portugal todos os meios financeiros que o contrato lhe fixava(3). No que respeita à apreciação do grau de concretização dos objectivos desportivos de Portugal nos Jogos Olímpicos de Pequim 2008, importa destacar o seguinte: O primeiro objectivo de Portugal que era obter cinco classificações de pódio (medalhas) não foi alcançado. Foram obtidas duas medalhas. 
Quadro 5. Classificações das federações desportivas por categoria de resultado

\begin{tabular}{|c|c|c|c|c|c|c|c|}
\hline \multicolumn{8}{|c|}{$\begin{array}{l}\text { Federações que obtiveram } \\
\text { lugar/Desistência }\end{array}$} \\
\hline & \multirow[b]{2}{*}{ Federações } & \multirow{2}{*}{$\begin{array}{l}\text { N. }{ }^{\circ} \text { de } \\
\text { praticantes } \\
\text { desportivos que } \\
\text { participaram nos } \\
\text { Jogos Olímpicos }\end{array}$} & \multicolumn{4}{|c|}{ Classificações } & \multirow[b]{2}{*}{$\begin{array}{l}\text { N. }{ }^{\circ} \text { de } \\
\text { classific. } \\
\text { possíveis } \\
\text { de obter }\end{array}$} \\
\hline & & & Medalha & $\begin{array}{l}\text { do } 4 .^{\circ} \text { ao } \\
8 .^{\circ} \text { lugar }\end{array}$ & $\begin{array}{l}\text { do } 9 .^{\circ} \text { ao } \\
16 .^{\circ} \text { lugar }\end{array}$ & $\begin{array}{l}\text { acima do } \\
16 . \% \\
\text { Desist. }\end{array}$ & \\
\hline 1 & Atletismo & 27 & 1 & 1 & 3 & 23 & 28 \\
\hline 2 & Triatlo & 3 & 1 & & & 2 & 3 \\
\hline 3 & Vela & 8 & & 3 & 2 & & 5 \\
\hline 4 & Taekwondo & 1 & & 1 & & & 1 \\
\hline 5 & Remo & 2 & & 1 & & & 1 \\
\hline 6 & Judo & 5 & & 1 & 4 & & 5 \\
\hline$?$ & Canoagem & 4 & & & 4 & & 4 \\
\hline 8 & Trampolins & 2 & & & 2 & & 2 \\
\hline 9 & Tiro com Arco & 1 & & & & 1 & 1 \\
\hline 10 & Tiro com Armas de Caça & 1 & & & & 1 & 1 \\
\hline 11 & Badmington & 2 & & & & 2 & 2 \\
\hline 12 & Ciclismo & 2 & & & & 2 & 2 \\
\hline 13 & Esgrima & 2 & & & & 2 & 2 \\
\hline 14 & Tiro & 1 & & & & 2 & 2 \\
\hline 15 & Equestre & 3 & & & & 3 & 3 \\
\hline 16 & Ténis de Mesa & 3 & & & & 3 & 3 \\
\hline \multirow[t]{2}{*}{17} & Natação & 10 & & & & 14 & 14 \\
\hline & Total & 77 & 2 & 7 & 15 & 55 & 79 \\
\hline
\end{tabular}

Quadro 6. Comparação dos objectivos fixados para Pequim 2008 e resultados obtidos em Atenas 2004

\begin{tabular}{|c|c|c|c|c|}
\hline \multicolumn{5}{|c|}{ Objectivos fixados para Pequim 2008 e resultados obtidos em Atenas 2004} \\
\hline & \multicolumn{2}{|c|}{ Jogos Olímpicos } & \multirow{2}{*}{\multicolumn{2}{|c|}{ Variação }} \\
\hline & \multirow{2}{*}{$\begin{array}{l}\text { Atenas } 2004 \\
\text { Resultados obtidos }\end{array}$} & \multirow{2}{*}{$\begin{array}{l}\text { Pequim } 2008 \\
\text { Objectivos fixados no } \\
\text { contrato }\end{array}$} & & \\
\hline & & & Absoluta & {$[\%]$} \\
\hline Classificações de pódio (medalha) & 3 & 5 & 2 & $67 \%$ \\
\hline Classificações do $4 .{ }^{\circ}$ ao $8 .{ }^{\circ}$ lugar (diploma) & 10 & 12 & 2 & $20 \%$ \\
\hline Número de modalidades presentes & 17 & 18 & 1 & $6 \%$ \\
\hline
\end{tabular}

O segundo objectivo de Portugal que era obter doze classificações correspondentes a diplomas (do $4 .^{\circ}$ ao 8. ${ }^{\circ}$ lugar) não foi alcançado, na medida em que foram obtidas sete classificações.
O terceiro objectivo de Portugal que era estar representado com 18 modalidades desportivas não foi atingido, na medida em que esteve representado por 17 modalidades. 
Objectivos e resultados alcançados por Portugal

\begin{tabular}{|c|c|c|c|c|}
\hline & Medida do resultado & $\begin{array}{l}\text { Objectivos para } \\
\text { Pequim } 2008\end{array}$ & $\begin{array}{l}\text { Resultados } \\
\text { alcançados em } \\
\text { Pequim } 2008\end{array}$ & Desvio \\
\hline 1 & Medalhas & 5 & 2 & -3 \\
\hline 2 & Diplomas $\left(4^{\circ}\right.$ ao $\left.8 .^{\circ}\right)$ & 12 & $?$ & -5 \\
\hline 3 & Modalidades presentes & 18 & 17 & -1 \\
\hline & Pontuação obtida [a] & 60 & 28 & -32 \\
\hline
\end{tabular}

\begin{tabular}{|c|c|}
\hline \multicolumn{2}{|c|}{ Apoios financeiros concedidos ao Comité Olímpico de Portugal } \\
\hline Projecto & Valor do contrato $2005 / 2008$ \\
\hline Gestão do Projecto Pequim & $630.000 €$ \\
\hline Projecto Pequim - Federações & $10.812 .876 €$ \\
\hline Subtotal & $11.442 .876 €$ \\
\hline Missão a Pequim 2008 & $700.000 €$ \\
\hline Total & $12.142 .876 €$ \\
\hline
\end{tabular}

\begin{tabular}{l|l|l|l}
\multicolumn{2}{l}{ Custos da missão olímpica } & \\
\hdashline & $\begin{array}{l}\text { Valor do contrato } \\
2008\end{array}$ & $\begin{array}{l}\text { N. de Praticantes } \\
\text { desportivos }\end{array}$ & Pusto por \\
praticante
\end{tabular}

Quadro 9. Custos da missão olímpica

\begin{tabular}{l|l|l} 
Custo por medalha e por diploma & \\
\hdashline Custo total do Projecto Pequim 2008 & $12.142 .876 €$ & $12.142 .876 €$ \\
\hline N. ${ }^{0}$ de medalhas / diplomas & 2 & 7 \\
\hline Custo por medalha / diploma & $6.071 .438 €$ & $1.734 .697 €$ \\
\hline
\end{tabular}

Quadro 7. Objectivos e resultados alcançados por Portugal

(a) A pontuação obtida não era um objectivo fixado no contrato programa. Foi anunciado pelo Comité Olímpico de Portugal, no sítio na Internet do jornal Expresso, em www.expresso.pt, em 13-08-2008.
Quadro 8. Apoios financeiros concedidos ao Comité Olímpico de Portugal por projecto, Pequim 2008
Esta é a verdade factual da participação de Portugal. Dos três objectivos fixados, Portugal não teve capacidades para alcançar qualquer deles.

\section{Custos do Projecto Pequim 2008}

O Projecto Pequim 2008 teve início em Janeiro de 2005 e a sua conclusão em Agosto de 2008. Durante 44 meses foram asseguradas especiais condições de preparação aos praticantes desportivos e selecções nacionais que reuniam condição desportiva para obterem classificações susceptíveis de concretizarem os objectivos fixados para os Jogos Olímpicos de Pequim 2008.

Para assegurar a concretização dos objectivos do Projecto Pequim 2008, o Estado Português através do Instituto do Desporto de Portugal(2) disponibilizou do Orçamento de Estado, Programa de Investimentos e Despesas de Desenvolvimento da Administração Central (PIDDAC), os meios financeiros, que ascenderam a 11.442.876€. A este mon- 
tante acresce um financiamento suplementar de $700.000 €$ destinado a custear as despesas com a missão a Pequim 2008, o que totaliza um valor global de $12.142 .876 €$.

Do montante total despendido, o valor efectivamente destinado à preparação dos praticantes desportivos e às bolsas olímpicas foi de $10.812 .876 €$, montante correspondente a $89 \%$ do total concedido(3). Para realizar a gestão do Projecto Pequim 2008 foram atribuídos ao Comité Olímpico de Portugal $630.000 €$, que corresponde a $5,2 \%$ do montante total despendido e a uma despesa mensal de $14.318 €(3)$.

Relativamente aos custos da missão de Portugal o apoio concedido de $700.000 €$, para um total de 77 praticantes desportivos, corresponde a um montante de $9.090 €$ por praticante.

\section{Custos por medalha e por diploma}

Tendo em conta as 2 medalhas alcançadas e o custo do Projecto Pequim 2008, o valor necessário despen- der para ser obtida uma medalha foi de 6.071.438€. Considerando as 7 classificações obtidas até ao $8 .^{\circ}$ lugar, o custo de cada classificação foi de $1.734 .697 €$.

\section{Apoios financeiros concedidos às federações desporti- vas e classificações obtidas}

As 3 federações desportivas que maiores apoios financeiros receberam no âmbito do Projecto Pequim 2008, até final do ano de 2007 (b) foram, de forma destacada, a de Atletismo, Vela e Judo, cujo somatório ascendeu a $3.755 .931,20 €(3)$. Estas federações correspondem a (18\%) e receberam $61 \%$ dos financiamentos atribuídos até 2007 às federações desportivas que participaram nos Jogos Olímpicos. Por outro lado, releva-se também, que estas 3 federações obtiveram $64 \%$ da pontuação de mérito desportivo de Portugal.

As federações desportivas que menores apoios tiveram foram as de Badminton, Ténis de Mesa, Tiro com Arco e Taekwondo que em conjunto receberam $82.674,09 €(3)$,

Quadro 11. Valor dos apoios concedidos de 2005 a 2007 às federações desportivas e resultados obtidos

\begin{tabular}{|c|c|c|c|c|}
\hline \multicolumn{5}{|c|}{ Valor dos apoios concedidos às federações desportivas } \\
\hline & Federação & $\begin{array}{l}\text { Valor dos apoios } \\
\text { concedidos de } 2005 \text { a } \\
2007 \text { (b) }\end{array}$ & $\begin{array}{l}\text { N. }{ }^{\circ} \text { de class. até } \\
\text { ao } 8 .^{\circ} \text { lugar }\end{array}$ & N. ${ }^{\circ}$ pontos obtidos \\
\hline 1 & Atletismo & $1.845 .995,75 €$ & 2 & $9(32 \%)$ \\
\hline 2 & Vela & $1.103 .409,82 €$ & 3 & $?[25 \%)$ \\
\hline 3 & Judo & $806.525,63 €$ & 1 & $2(7 \%)$ \\
\hline 4 & Canoagem & $450.930,90 €$ & & \\
\hline 5 & Natação & $303.132,09 €$ & & \\
\hline 6 & Triatlo & $276.464,96 €$ & 1 & $?$ \\
\hline$?$ & Tiro com Armas Caça & $233.666,66 €$ & & \\
\hline 8 & Trampolins & $213.284,59 €$ & & \\
\hline 9 & Ciclismo & $212.779,95 €$ & & \\
\hline 10 & Equestre & $171.888,09 €$ & & \\
\hline 11 & Remo & $161.562,46 €$ & 1 & $1(3,6 \%)$ \\
\hline 12 & Esgrima & $145.042,43 €$ & & \\
\hline 13 & Tiro & $124.625,00 €$ & & \\
\hline 14 & Badminton & $41.202,68 €$ & & \\
\hline 15 & Ténis Mesa & $22.033,91 €$ & & \\
\hline 16 & Tiro Arco & $10.000,00 €$ & & \\
\hline \multirow[t]{2}{*}{17} & Taekwondo & $9.437,50 €$ & 1 & $2(7 \%)$ \\
\hline & Total & $6.131 .982,42 €$ & 9 & 28 \\
\hline
\end{tabular}

(b) - Nesta data, o valor dos apoios concedidos em 2008 às federações não está disponível representam $24 \%$ das federações e receberam $1,3 \%$ dos financiamentos atribuídos até 2007 às federações desportivas que participaram nos Jogos Olímpicos. As federações desportivas que não ções até ao $16 .^{\circ}$ lugar foram 9 , e representam $53 \%$ das federações, contudo receberam financiamentos no valor de $1.264 .370,81 €$, que representa $21 \%$ dos financiamentos atribuídos até 2007 às federações desportivas que participaram nos Jogos Olímpicos obtiveram classifica- 


\begin{tabular}{l|l} 
Taxa de "Medalhamento" & \\
\hline N. ${ }^{\circ}$ de medalhas obtidas & 2 \\
\hline População residente & 10.617 .575 \\
\hline Taxa de "Medalhamento" & 5.308 .788 \\
\hline
\end{tabular}

Quadro 13. Grau de concretização dos objectivos e resultados obtidos por Portugal em Pequim 2008 e Atenas 2004

\begin{tabular}{|c|c|c|c|c|c|}
\hline \multicolumn{6}{|c|}{ Objectivos e resultados obtidos por Portugal } \\
\hline & Medida do resultado & $\begin{array}{l}\text { Resultados } \\
\text { alcançados } \\
\text { em Atenas } \\
2004\end{array}$ & $\begin{array}{l}\text { Objectivos } \\
\text { para Pequim } \\
2008\end{array}$ & $\begin{array}{l}\text { Resultados } \\
\text { alcançados } \\
\text { em Pequim } \\
2008\end{array}$ & $\begin{array}{l}\text { Variação face a } \\
\text { Atenas } 2004\end{array}$ \\
\hline 1 & Medalhas & 3 & 5 & 2 & -1 \\
\hline 2 & Diplomas $\left(4 .^{\circ}\right.$ ao $\left.8 .^{\circ}\right)$ & 10 & 12 & $?$ & -3 \\
\hline \multirow[t]{2}{*}{3} & Modalidades presentes & 16 & 18 & 17 & 1 \\
\hline & Pontuação obtida (a) & 44 & 60 & 28 & -16 \\
\hline
\end{tabular}

(a) A pontuação obtida não era um objectivo fixado no contrato programa. Foi anunciado pelo Comité Olímpico de Portugal, no sítio na Internet do jornal Expresso, em www.expresso.pt, em 13-08-2008.

Quadro 14. Mérito desportivo e classificações obtidas por Portugal nos últimos 4 Jogos Olímpicos

\begin{tabular}{|c|c|c|c|c|c|c|c|c|}
\hline \multicolumn{9}{|c|}{ Mérito desportivo e classificações obtidas nos 4 Jogos Olímpicos } \\
\hline \multirow[b]{2}{*}{ Classificação } & \multicolumn{2}{|c|}{ Atlanta 1996} & \multicolumn{2}{|c|}{ Sydney 2000} & \multicolumn{2}{|c|}{ Atenas 2004} & \multicolumn{2}{|c|}{ Pequim 2008} \\
\hline & $\begin{array}{l}\mathrm{N} .{ }^{\circ} \text { de } \\
\text { classific. }\end{array}$ & Pontuação & $\begin{array}{l}\mathrm{N} .{ }^{\circ} \text { de } \\
\text { classific. }\end{array}$ & Pontuação & $\begin{array}{l}\text { N. }{ }^{\circ} \text { de } \\
\text { classific. }\end{array}$ & Pontuação & $\begin{array}{l}\text { N. }{ }^{\circ} \text { de } \\
\text { classific. }\end{array}$ & Pontuação \\
\hline Ouro & 1 & 8 & & & & & 1 & 8 \\
\hline Prata & & & & & 2 & 14 & 1 & $?$ \\
\hline Bronze & 1 & 6 & 2 & 12 & 1 & 6 & & \\
\hline sub-total & 2 & 14 & 2 & 12 & 3 & 20 & 2 & 15 \\
\hline 4. ${ }^{\circ}$ lugar & 2 & 10 & 1 & 5 & & & 1 & 5 \\
\hline 5. ${ }^{\circ}$ ugar & & & 1 & 4 & 2 & 8 & & \\
\hline $6 .^{\circ}$ lugar & 1 & 3 & 1 & 3 & 2 & 6 & & \\
\hline 7. ${ }^{\circ}$ lugar & 4 & 4 & 3 & 6 & 4 & 8 & 2 & 4 \\
\hline 8. ${ }^{\circ}$ lugar & & & & & 2 & 2 & 4 & 4 \\
\hline sub-total & $?$ & 17 & 6 & 18 & 10 & 24 & 7 & 13 \\
\hline Total & 9 & 31 & 8 & 30 & 13 & 44 & 9 & 28 \\
\hline
\end{tabular}

Procurámos estabelecer uma relação entre o valor dos apoios totais concedidos até 2007 às federações desportivas e as classificações por elas obtidas. Nas 2 federações que receberam maior volume de apoios parece verificar-se a existência de uma relação directa entre o financiamento concedido e o número de classificações obtidas. O Atletismo e a Vela foram as federações desportivas que receberam maiores 
apoios, mas também as que obtiveram melhores resultados, através de maior número de classificações até ao $8 .^{\circ}$ lugar e maior número de pontos. Encontramos uma relação inversa nas federações de Canoagem, Natação, Tiro com Armas de Caça, Trampolins e Ciclismo, cada uma recebeu apoios superiores a $200.000 €$ e não obteve qualquer resultado até ao $8 .^{\circ}$ lugar.

\section{Número de habitantes por medalha - taxa de "medalhamento"}

$\mathrm{O}$ indicador número de habitantes de um país por medalha fornece informação sobre a base de recrutamento de praticantes desportivos que poderá revelar a capacidade do sistema desportivo de um dado país produzir resultados. Este indicador é usualmente designado por taxa de "medalhamento" de cada país. Tendo em conta que a população residente em Portugal, em 2008(5) é de 10.617.575 habitantes, a taxa de "medalhamento" de Portugal, nos Jogos Olímpicos de Pequim 2008 foi de 1 medalha por 5.308.788 milhões de habitantes.

\section{DISCUSSÃO}

\section{Resultados obtidos pelos praticantes}

\section{desportivos e federações desportivas}

O desempenho de Portugal nos Jogos Olímpicos em Pequim 2008 teve um nível inferior ao de Atenas 2004 em todas as categorias dos objectivos. 3 medalhas obtidas em Atenas, 2 em Pequim. 10 diplomas em Atenas, 7 em Pequim. 44 pontos obtidos em Atenas, 28 em Pequim(1).

No período de 12 anos e 4 Jogos Olímpicos o número de medalhas que Portugal arrecadou nunca ultrapassou o valor de 3, máximo atingido em Atenas 2004. Nos outros 3 Jogos Olímpicos o número de medalhas obtido foi sempre de 2 , apesar de diferentes no seu valor ${ }^{(1)}$.

O número de diplomas (classificações do $4 .^{\circ}$ ao $8 .^{\circ}$ lugar) obtido em Pequim 2008 foi igual ao obtido em Atlanta 1996 e superior em 1 a Sydney 2000. Ficou contudo, 3 abaixo da melhor classificação obtida em Atenas 2004, com 10 diplomas ${ }^{(1)}$. O desempenho desportivo de Portugal nos Jogos Olímpicos de Pequim 2008 relativamente aos Jogos Olímpicos de Atlanta 1996, manifestou uma manutenção do número de medalhas em 2 e do número de classificações do $4 .^{\circ}$ ao $8 .^{\circ}$ lugar em 7 . Ou seja, decorridos 12 anos, apesar de Portugal dispor, ao nível do desporto olímpico, de melhores condições financeiras e materiais, verificou-se um desempenho idêntico ao de Atlanta 1996.

Relativamente a Sydney 2000(1), em Pequim 2008 o número de medalhas manteve-se em 2 e o número de classificações do $4 .^{\circ}$ ao $8 .^{\circ}$ lugar aumentou de 6 para 7. Ou seja, em Pequim 2008 verificou-se um desempenho ligeiramente superior ao de Sydney 2000.

Relativamente a Atenas 2004(1), em Pequim 2008 o número de medalhas sofreu uma redução de 1 e o número de classificações do $4 .^{\circ}$ ao $8 .^{\circ}$ lugar foi também menor em 3, de 10 em Atenas 2004, para 7 em Pequim 2008.

Apesar da estabilidade financeira conseguida para a execução do projecto de preparação olímpica, da contratualização quadrienal dos apoios e da condução em exclusivo, pelo Comité Olímpico de Portugal, da preparação olímpica o desempenho desportivo de Portugal teve um nível inferior em Pequim 2008 do que em Atenas 2004.

A competitividade das federações desportivas pode ser aferida pelo critério do número de classificações obtidas, método que possibilita distinguir as federações desportivas em 3 grupos, consoante a sua competitividade nos últimos 4 Jogos Olímpicos:

1 - Modalidades que obtiveram medalha;

2 - Modalidades que obtiveram classificação correspondente a diploma $\left(4 .^{\circ}-8 .^{\circ}\right.$ lugar $)$

3 - Modalidades que nunca obtiveram classificação correspondente a diploma.

As federações mais competitivas e com um melhor desempenho nos últimos 4 Jogos Olímpicos são as integradas no grupo I, Atletismo, Vela, Judo, Triatlo e o Ciclismo, as demais manifestam um nível de desempenho inferior e integram-se nos grupos II e III.

\section{Custos do Projecto Pequim 2008}

No Projecto Pequim 2008 o montante afectado às federações desportivas destinado à preparação dos praticantes desportivos e às bolsas, foi inferior em 154.241€, ao correspondente no Projecto Atenas 2004. Donde se conclui que os custos da preparação dos praticantes desportivos para os Jogos Olímpicos de Pequim 2008 foram inferiores aos custos do Projecto Atenas 2004. 
Quadro 15. Grupos de federações desportivas segundo a competitividade nos 4 Jogos Olímpicos

\begin{tabular}{|c|c|c|c|c|c|c|c|c|c|c|c|c|}
\hline \multicolumn{13}{|c|}{ Grupos de modalidades segundo as classificações obtidas nos 4 Jogos Olímpicos } \\
\hline & & \multirow[b]{2}{*}{ Federações } & \multicolumn{2}{|c|}{ Atlanta 1996} & \multicolumn{2}{|c|}{ Sydney 2000} & \multicolumn{2}{|c|}{ Atenas 2004} & \multicolumn{2}{|c|}{ Pequim 2008} & \multicolumn{2}{|l|}{ Total } \\
\hline & & & Med. & $\begin{array}{l}4 .^{\circ} \\
\text { ao } \\
8 .{ }^{\circ}\end{array}$ & Med. & $\begin{array}{l}4 .^{\circ} \\
\text { ao } \\
8 .^{\circ}\end{array}$ & Med. & $\begin{array}{l}4 .^{\circ} \\
\text { ao } \\
8 .{ }^{\circ}\end{array}$ & Med. & $\begin{array}{l}4 .^{\circ} \mathrm{ao} \\
8 .^{\circ}\end{array}$ & Med. & $4 .^{\circ}$ ao $8 .^{\circ}$ \\
\hline \multirow{5}{*}{ I } & 1 & Atletismo & 1 & 2 & 1 & & 2 & 2 & 1 & 1 & 5 & 5 \\
\hline & 2 & Vela & 1 & 2 & & 3 & & 3 & & 3 & 1 & 11 \\
\hline & 3 & Judo & & & 1 & 1 & & 2 & & 1 & 1 & 4 \\
\hline & 4 & Triatlo & & & & & & 1 & 1 & & 1 & 1 \\
\hline & 5 & Ciclismo & & & & & 1 & & & & 1 & 0 \\
\hline \multirow{8}{*}{ II } & 6 & Voleibol Praia & & 1 & & 1 & & & & & 0 & 2 \\
\hline & 7 & Canoagem & & & & & & 1 & & & 0 & 1 \\
\hline & 8 & Tiro & & & & 1 & & & & & 0 & 1 \\
\hline & 9 & Tiro A. Caça & & 1 & & & & & & & 0 & 1 \\
\hline & 10 & Futebol & & 1 & & & & & & & 0 & 1 \\
\hline & 11 & Trampolins & & & & & & 1 & & & 0 & 1 \\
\hline & 12 & Taekwondo & & & & & & & & 1 & 0 & 1 \\
\hline & 13 & Remo & & & & & & & & 1 & 0 & 1 \\
\hline \multirow{11}{*}{ III } & 14 & Esgrima & & & & & & & & & 0 & 0 \\
\hline & 15 & Badminton & & & & & & & & & 0 & 0 \\
\hline & 16 & Equestre & & & & & & & & & 0 & 0 \\
\hline & 17 & Ginástica & & & & & & & & & 0 & 0 \\
\hline & 18 & Lutas Amador. & & & & & & & & & 0 & 0 \\
\hline & 19 & Natação & & & & & & & & & 0 & 0 \\
\hline & 20 & Pent. Moderno & & & & & & & & & 0 & 0 \\
\hline & 21 & Ténis & & & & & & & & & 0 & 0 \\
\hline & 22 & Tiro com Arco & & & & & & & & & 0 & 0 \\
\hline & & Subtotal & 2 & $?$ & 2 & 6 & 3 & 10 & 2 & $?$ & 9 & 30 \\
\hline & & Total & 9 & & 8 & & 13 & & 9 & & 39 & \\
\hline
\end{tabular}

Quadro 16. Apoios concedidos ao Comité Olímpico de Portugal, Projectos Pequim 2008 e Atenas 2004

\begin{tabular}{l|l|l|l}
\hline Apoios financeiros concedidos ao Comité Olímpico de Portugal & \\
\hline Projecto & $\begin{array}{l}\text { Projecto Atenas 2004 Valores } \\
\text { dos contratos 2001/2004 }\end{array}$ & $\begin{array}{l}\text { Projecto Pequim 2008 } \\
\text { Valores dos contratos 2005/ / } \\
\text { Vação face a Atenas } \\
2008\end{array}$ & 2004 \\
\hline Gestão do Projecto & $234.796 €$ & $630.000 €$ & $395.204 €$ \\
\hline Federações & $10.967 .117 €$ & $10.812 .876 €$ & $-154.241 €$ \\
\hline Total & $11.201 .913 €$ & $11.442 .876 €$ & $240.963 €$ \\
\hline Missão Olímpica & $650.000 €$ & $700.000 €$ & $50.000 €$ \\
\hline
\end{tabular}


Quadro 17. Apoios financeiros concedidos ao Comité Olímpico de Portugal do Projecto Atlanta 1996 a Pequim 2008

Apoios financeiros concedidos ao Comité Olímpico de Portugal para o Projecto Atlanta 1996, Sydney 2000, Atenas 2004 e

Pequim 2008

\begin{tabular}{|c|c|c|c|c|c|c|c|}
\hline & \multirow{2}{*}{$\begin{array}{l}\text { Projecto } \\
\text { Atlanta } 1996 \\
\text { Valores dos } \\
\text { contratos } \\
1995 \text { - } 1996\end{array}$} & \multicolumn{2}{|c|}{ Projecto Sydney 2000} & \multicolumn{2}{|c|}{ Projecto Atenas 2004} & \multicolumn{2}{|c|}{ Projecto Pequim 2008} \\
\hline & & $\begin{array}{l}\text { Valores dos } \\
\text { contratos } \\
1997-2000\end{array}$ & Variação & $\begin{array}{l}\text { Valores dos } \\
\text { contratos } \\
2001-2004\end{array}$ & Variação & $\begin{array}{l}\text { Valores do } \\
\text { contrato } 2005 \\
-2008\end{array}$ & Variação \\
\hline Gestão do Projecto & $199.520 €$ & $274.340 €$ & $37,5 \%$ & $234.796 €$ & $-14,4 \%$ & 630.000 & $268,3 \%$ \\
\hline Missão Olímpica & $324.218 €$ & $349.157 €$ & $7,7 \%$ & $650.000 €$ & $86,1 \%$ & 700.000 & $7,7 \%$ \\
\hline $\begin{array}{l}\text { Subtotal } \\
\text { Comité Olímpico }\end{array}$ & $523.738 €$ & $623.497 €$ & $19,0 \%$ & $964.796 €[a]$ & $54,7 \%$ & 1.330 .000 & $37,9 \%$ \\
\hline $\begin{array}{l}\text { Subtotal } \\
\text { Federações }\end{array}$ & $5.561 .597 €$ & $8.927 .375 €$ & $60,5 \%$ & 10.967.117€ & $22,9 \%$ & 10.812 .876 & $-1,4 \%$ \\
\hline Total & $6.085 .334 €$ & $9.550 .872 €$ & $56,9 \%$ & $11.931 .912 €$ & $24,1 \%$ & $12.142 .876 €$ & $1,8 \%$ \\
\hline \% do apoio COP/Fed. & $9 \%$ & $7 \%$ & & $9 \%$ & & $11 \%$ & \\
\hline
\end{tabular}

(a) inclui um montante $80.000 €$ destinado aos praticantes qualificados

Quadro 18. Financiamento da Missão aos últimos 4 Jogos Olímpicos e custo por praticante da missão

\begin{tabular}{l|l|l|l|l|l}
\hline Financiamento da missão aos Jogos Olímpicos e custo por praticante da missão & \\
\hline Jogos Olímpicos & Valor do contrato & Variação & $\begin{array}{l}\text { N. }{ }^{\circ} \text { de praticantes } \\
\text { desportivos } \\
\text { participantes }\end{array}$ & $\begin{array}{l}\text { Custo por } \\
\text { praticante }\end{array}$ & Variação \\
\hline Atlanta 1996 & $324.218 €$ & nd & 101 & $3.210 €$ & nd \\
\hline Sydney 2000 & $349.157 €$ & $7,7 \%$ & 62 & $7.632 €$ & $75,0 \%$ \\
\hline Atenas 2004 & $650.000 €$ & $86,1 \%$ & 82 & $9.927 €$ & $40,7 \%$ \\
\hline Pequim 2008 & $700.000 €$ & $7,7 \%$ & 77 & $14,7 \%$ \\
\hline
\end{tabular}

Quadro 19. Custo por medalha e por diploma em Pequim 2008 e Atenas 2004

\begin{tabular}{|c|c|c|c|}
\hline \multicolumn{4}{|c|}{ Custo por medalha e por diploma Pequim 2008 e Atenas 2004} \\
\hline & Projecto Atenas 2004 & Projecto Pequim 2008 & Variação \\
\hline Custo total do Projecto & $11.931 .913 €$ & $12.142 .876 €$ & $1,8 \%$ \\
\hline N. ${ }^{\circ}$ de medalhas & 3 & 2 & $-66,7 \%$ \\
\hline Custo por medalha & $3.977 .304 €$ & $6.071 .438 €$ & $52,7 \%$ \\
\hline N. ${ }^{\circ}$ de classificações até ao 8..$^{\circ}$ ugar & 13 & $?$ & $-53,8 \%$ \\
\hline Custo por classificação até ao $8 .^{\circ}$ lugar & $917.839 €$ & $1.734 .697 €$ & $88,9 \%$ \\
\hline
\end{tabular}


Quadro 20. Número de habitantes por medalha - taxa de "medalhamento", Pequim 2008 e Atenas 2004

\begin{tabular}{l|l|l} 
Taxa de "Medalhamento" & Atenas 2004 & Pequim 2008 \\
\hline N. ${ }^{\circ}$ de medalhas obtidas & 3 & 2 \\
\hline População residente (2003/2008) & 10.356 .117 & 10.617 .575 \\
\hline Taxa de "Medalhamento" & 3.452 .039 & 5.308 .788 \\
\hline
\end{tabular}

Quadro 21. Número de habitantes por medalha - taxa de "medalhamento" por país da União Europeia 27

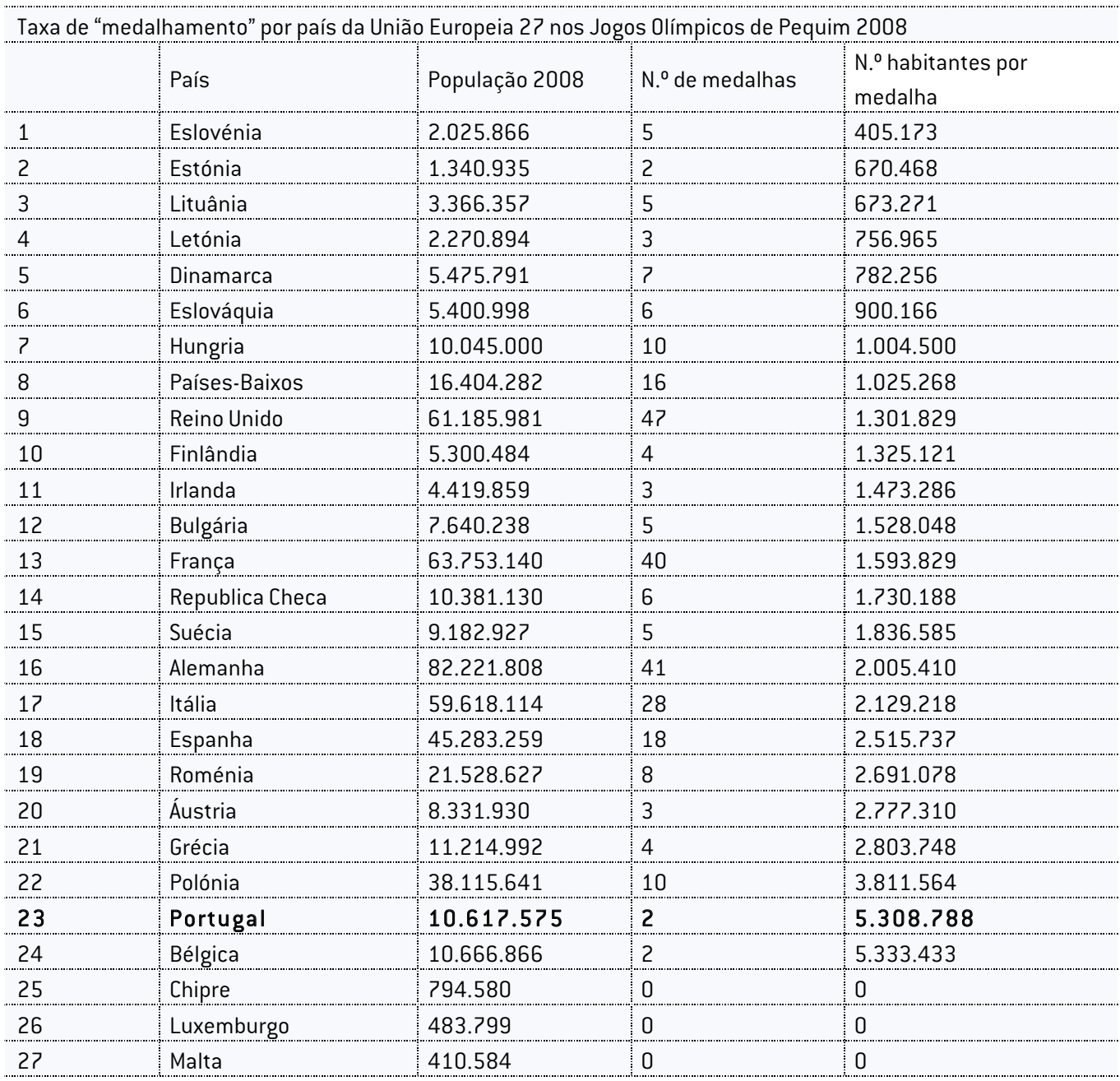


Quadro 22. Comparação do indicador, $n .^{\circ}$ de medalhas e $n .^{\circ}$ habitantes por medalha Pequim 2008 e Atenas 2004

Os 27 países da União Europeia e indicadores desportivos

\begin{tabular}{|c|c|c|c|c|c|c|}
\hline & $\begin{array}{l}\text { País } \\
\text { União Europeia } 27\end{array}$ & $\begin{array}{l}\text { N. }{ }^{\circ} \text { de } \\
\text { Medalhas } \\
\text { Atenas } \\
2004\end{array}$ & $\begin{array}{l}\text { N. }{ }^{\circ} \text { de } \\
\text { Medalhas } \\
\text { Pequim } \\
2008\end{array}$ & $\begin{array}{l}\text { N. }{ }^{\circ} \text { habitantes por } \\
\text { medalha Pequim } \\
2008\end{array}$ & $\begin{array}{l}\text { Variação: } \text {. }^{\circ} \text { de } \\
\text { medalhas } \\
\text { Atenas } 2004 \text { / } \\
\text { Pequim } 2008\end{array}$ & $\begin{array}{l}\text { Variação: posição } \\
\text { n. }{ }^{\circ} \text { habitantes por } \\
\text { medalha Atenas } \\
2004 \text { / Pequim } \\
2008\end{array}$ \\
\hline 1 & Reino Unido & 30 & 47 & 1.301 .829 & 17 & 8 \\
\hline 2 & Alemanha & 49 & 41 & 2.005 .410 & -8 & -2 \\
\hline 3 & França & 33 & 40 & 1.593 .829 & $?$ & 3 \\
\hline 4 & Itália & 32 & 28 & 2.129 .218 & -4 & -2 \\
\hline 5 & Espanha & 19 & 18 & 2.515 .737 & -1 & 0 \\
\hline 6 & Países-Baixos & 22 & 16 & 1.025 .268 & -6 & -1 \\
\hline$?$ & Hungria & 17 & 10 & 1.004 .500 & -7 & -4 \\
\hline 8 & Polónia & 10 & 10 & 3.811 .564 & 0 & 0 \\
\hline 9 & Roménia & 19 & 8 & 2.691 .078 & -11 & -10 \\
\hline 10 & Dinamarca & 8 & $?$ & 782.256 & -1 & 0 \\
\hline 11 & Eslováquia & 6 & 6 & 900.166 & 0 & 2 \\
\hline 12 & Republica Checa & 8 & 6 & 1.730 .188 & -2 & -2 \\
\hline 13 & Bulgária & 12 & 5 & 1.528 .048 & -7 & -8 \\
\hline 14 & Eslovénia & 4 & 5 & 405.173 & 1 & 1 \\
\hline 15 & Lituânia & 3 & 5 & 673.271 & 2 & $?$ \\
\hline 16 & Suécia & $?$ & 5 & 1.836 .585 & -2 & -2 \\
\hline 17 & Finlândia & 2 & 4 & 1.325 .121 & 2 & 9 \\
\hline 18 & Grécia & 16 & 4 & 2.803 .748 & -12 & -15 \\
\hline 19 & Áustria & $?$ & 3 & 2.777 .310 & -4 & -9 \\
\hline 20 & Irlanda & 0 & 3 & 1.473 .286 & 3 & 16 \\
\hline 21 & Letónia & 0 & 3 & 756.965 & 3 & 22 \\
\hline 22 & Bélgica & 3 & 2 & 5.333 .433 & -1 & -4 \\
\hline 23 & Estónia & 3 & 2 & 670.468 & -1 & -1 \\
\hline 24 & Portugal & 3 & 2 & 5.308 .788 & -1 & -2 \\
\hline 25 & Chipre & 0 & 0 & 0 & 0 & 0 \\
\hline 26 & Luxemburgo & 0 & 0 & 0 & 0 & -2 \\
\hline 27 & Malta & 0 & 0 & 0 & 0 & -4 \\
\hline
\end{tabular}

Um projecto que manifestou um aumento de custos foi a gestão do Projecto que passou a ser efectuada em exclusivo pelo Comité Olímpico de Portugal, teve uma despesa quadrienal de $630.000 €$, o que corresponde a um encargo mensal de $14.318 €$.

O valor dos apoios concedidos ao Comité Olímpico de Portugal representou $11 \%$ dos apoios concedidos às federações desportivas, mais $2 \%$ do que no Projecto Atenas 2004.

Relacionando o desempenho desportivo de Portugal e os meios financeiros afectados à preparação olímpica, conclui-se que no período de 12 anos (Atlanta 1996 - Pequim 2008) os meios financeiros aplicados aumentaram em $100 \%$, não tendo os resultados des- 
portivos acompanhado com qualquer crescimento. Especificamente para a missão aos Jogos Olímpicos de Pequim 2008, relativamente ao apoio concedido para a missão a Atenas 2004 verificou-se um aumento de $7,7 \%$. Ou seja, teve um custo de $9.090 €$ por praticante, enquanto para Atenas foi de $7.927 €$.

\section{Custo por medalha e por diploma}

Comprando a prestação desportiva em Pequim 2008 com a de Atenas 2004, tendo em conta as 3 medalhas alcançadas e o custo dos projectos olímpicos, o valor necessário despender para ser obtida uma medalha em Pequim 2008 foi de 6.071.438€ e em Atenas 2004 foi de 3.977.304 €. Para obter uma classificação até ao $8 .^{\circ}$ lugar, o custo em Atenas 2004 foi de 917.839€, enquanto em Pequim 2008 foi de 1.734.697 €.

\section{Número de habitantes por medalha - taxa de "medalhamento"}

No indicador número de habitantes por medalha o desempenho de Portugal nos Jogos Olímpicos de Pequim 2008 foi inferior ao dos Jogos Olímpicos de Atenas 2004, manifestou uma relação de 1 medalha por 5.308.788 habitantes em Pequim 2008, para uma medalha por 3.452.039 habitantes em Atenas 2004 . No âmbito dos 27 países da União Europeia (UE) a prestação de Portugal ao nível do número de medalhas obtidas permitiu posicionar Portugal no $21 .^{\circ}$ lugar, com a mesma prestação que a Bélgica e a Estónia. Atrás de Portugal ficaram apenas pequenos países que não obtiveram qualquer medalha, Chipre, Luxemburgo e Malta e cuja população não ultrapassa os 800.000 habitantes.

Ao nível da taxa de "medalhamento" medida pelo número de habitantes por medalha, a posição de Portugal no âmbito dos 27 países da União Europeia ainda é mais desfavorável, ocupando o $23 .^{\circ}$ lugar, com 5.308.788 habitantes por medalha, ficando posicionados atrás de Portugal a Bélgica, Chipre,

Luxemburgo e Malta.

Comparando o desempenho de Portugal nos Jogos olímpicos de Pequim 2008 com o de Atenas 2004 verificamos que não se registaram alterações significativas. Os 2 indicadores registaram em Pequim 2008 níveis inferiores de desempenho. Por um lado, Portugal obteve menos 1 medalha e, por outro, a posição, no que respeita ao número de habitantes por medalha desceu 2 lugares.
Em síntese as grandes conclusões são as seguintes: dos três objectivos desportivos fixados para Portugal nos Jogos Olímpico de Pequim 2008, não foi atingido nenhum.

Apesar da estabilidade financeira conseguida para a execução do projecto de preparação olímpica, da contratualização quadrienal dos apoios e da condução em exclusivo, pelo Comité Olímpico de Portugal, da preparação olímpica, o desempenho desportivo de Portugal teve um nível inferior em Pequim 2008 do que em Atenas 2004.

Para a execução do Projecto Pequim 2008 foi concedida ao Comité Olímpico de Portugal uma verba 12.142.876€, mas o montante afectado às federações desportivas destinado à preparação dos praticantes desportivos e às bolsas, foi inferior em 154.241€, ao correspondente no Projecto Atenas 2004.

No período de 12 anos (Atlanta 1996 - Pequim 2008) os meios financeiros aplicados na preparação olímpica aumentaram em $100 \%$, não tendo os resultados desportivos acompanhado com qualquer crescimento. No âmbito dos 27 países da União Europeia a prestação de Portugal ao nível do número de medalhas obtidas permitiu posicionar Portugal no 21. ${ }^{\circ}$ lugar, com a mesma prestação que a Bélgica e a Estónia. Atrás de Portugal ficaram apenas pequenos países que não obtiveram qualquer medalha.

\section{CORRESPONDÊNCIA}

\section{Alfredo Silva}

Escola Superior de Desporto de Rio Maior

Instituto Politécnico de Santarém

Avenida Dr. Mário Soares - Pavilhão Multiusos

2040-413 Rio Maior

Portugal

Telefone: + (351) 965071871

E-mail: alfredosilva@esdrm.pt 


\section{REFERÊNCIAS}

1. Avaliação dos Apoios à Participação de Portugal nos Jogos Olímpicos de Atenas 2004, Instituto do Desporto de Portugal, 2004 (documento não publicado).

2. Diário da Republica, $2^{\text {a }}$ série, N. ${ }^{\circ} 70$, de 11 de Abril de 2005.

3. Relatório do Programa de Preparação Olímpica 2006, Comité Olímpico de Portugal, 2007 (documento não publicado).
4. Relatório do Programa de Preparação Olímpica 2007, Comité Olímpico de Portugal, 2008 (documento não publicado).

5. Página Oficial do Comité Olímpico de Portugal http://www.comiteolimpicoportugal.pt/ - acedida em 2608-2008.

6. Pagina Oficial do Instituto do Desporto de Portugal www.idesporto.pt - acedida em 15-08-2008. 